\title{
Reseña. Javier Guerrero, Tecnologías del cuerpo. Exhibicionismo y visualidad en América Latina. Iberoamericana-Vervuert. Madrid- Fankfurt, 2014.
}

El libro de Javier Guerrero logra en casi trescientas páginas envolvernos en un estudio detallado del cuerpo, sus intervenciones y transformaciones en diferentes autores y artistas latinoamericanos; todo ello acompañado de 76 fotografías provenientes de archivos personales de los autores logrando una profundidad significativa en su análisis. Desde sus primeras páginas se indica cuál es su objeto de estudio: los cuerpos que no responden a la normalización heterosexual impuesta en América Latina. En un recorrido de cinco capítulos que dedica a Reinaldo Arenas, Salvador Novo, Armando Reverón, Fernando Vallejo y Mario Bellatin, explora la condición material de los cuerpos, alejándose de las dimensiones metafóricas que han operado sobre ellos. La introducción, "El cuerpo bajo sospecha", presenta el planteamiento teórico y político de cómo Guerrero abordará el tema del cuerpo. Plantea abordar las ficciones de artistas y escritores de América Latina que contienen una sexualidad "problemática" para centrarse en la confusión de sus propios cuerpos con sus representaciones: "me aproximo indistintamente a los cuerpos autorales y a sus autofiguraciones y producciones, como manera de exponer el complejo movimiento que no solamente organiza, su 
inteligibilidad, sino que también determina su contextura material” (20). La elección de los autores tiene como eje fundamental aquellos que contienen sexualidades disidentes que desmantelan el binarismo masculino/femenino y que rechazan las ideas homogéneas de cultura y nación definidas por la ciudad letrada latinoamericana. Para ello, Guerrero utiliza diferentes perspectivas teóricas que van dando "cuerpo" a su análisis del cuerpo, siendo las más importantes (entre otras) la idea de materialidad y género (21) donde plantea desde la perspectiva de Michel Foucault -biopolítica, anatomopolítica y monstruosidad- como fundantes de la historización normativa de los cuerpos. Junto a lo anterior, también propone la abyección como una forma de resistencia a esos poderes normativos. El materialismo de Jean Luc-Nancy es otro punto importante en el análisis, ya que plantea el concepto de excriptura que entiende al cuerpo como urgencia que reclama una escritura, donde "no es ni significante ni significado, es exterioridad, exposición, extensión de la fractura de la existencia” (25). Judith Butler y el concepto de performatividad es también fundamental para el análisis de los autores seleccionados, ya que para la autora, el sexo y el cuerpo son categorías generizadas que no están fuera del género ni lo causan, por ello abre la posibilidad de reformular los cuerpos. Esta reformulación será clave en el análisis de Guerrero porque propone que el viaje y la extranjería, la enfermedad y el archivo inciden en la política de estos cuerpos en América Latina y por ende, en los autores seleccionados.

El primer capítulo, "El reinado del cuerpo. Reescrituras de Reinaldo Arenas", ingresa al cuerpo del poeta cubano por medio del concepto de "escoria", donde un cuerpo transita por medio de fronteras físicas y simbólicas invisibles para así responder a la exclusión en que ha sido sometido. El cuerpo homosexual de Arenas, que amenaza el discurso revolucionario, ha sido desechado de Cuba como escoria "gusanera" y es expulsado de forma "natural" de la isla. Entonces ¿Cómo se materializa este cuerpo "gay" una vez que ha sido desechado? Guerrero responde que por medio de una reescritura que funciona en forma plástica. La reescritura de Arenas es un método de trabajo, ya que el autor reescribe casi todas 
CATEDRAL TOMADA: Revista de crítica literaria latinoamericana / Journal of Latin American Literary Criticism Reseña. Javier Guerrero, Tecnologías del cuerpo. Exhibicionismo y visualidad en América Latina. IberoamericanaVervuert. Madrid-Fankfurt, 2014.

sus obras en forma sistemática, casi obsesiva. Arenas compartía sus anécdotas y recibía comentarios de un grupo cercano de amigos, por lo tanto, su trabajo también fue colectivo, lo que tiene una doble acepción: por un lado la plasticidad de exhibirse y por otro, de formarse para activar su propia memoria. Por medio de muchas fotografías, Guerrero analiza los punctum de Arenas donde se exhibe a sí mismo como "gusano". Me parece muy importante en este capítulo el proceso de transformación del cuerpo del autor en las diferentes fotografías que Guerrero ha seleccionado, ya que muestran claramente cómo el cuerpo es primeramente un cuerpo escondido, luego un cuerpo celebrado $\mathrm{y}$, finalmente un cuerpo enfermo que se oculta (ya que casi no hay fotografías de último periodo). El capítulo finaliza con una fotografía de un desnudo de Arenas detrás de una mampara de baño que devuelve una imagen distorsionada. Es precisamente ese cuerpo, que ha vivido las paradojas del exilio y la enfermedad, que retorna como cuerpo excrito desde los archivos de Princeton y sexuado fuera de Cuba.

"Salvador Novo y su estatua" es el segundo capítulo dedicado al escritor mexicano que, desde sus crónicas de viaje, se presenta como un cuerpo que se sexúa en el extranjero. Guerrero apunta en este capítulo al concepto de "archivo plástico" para analizar no sólo las crónicas de viaje, sino los artefactos del autor mexicano que gustaba de exhibir. El viaje es el tema fundamental, aunque Novo tenía que viajar constantemente por sus compromisos, le disgustaban los viajes, por ello convierte este incómodo momento en escritura. De este modo, el viaje plasmado en diferentes géneros literarios (diario de viaje, crónica, memoria) abre la posibilidad de materializar el deseo. Así el travestismo, la escritura cifrada y el cambio de lengua son estrategias que desafían a la norma. Los cuerpos deseados se convierten en "materiales", palabra clave de Novo para referirse a ellos, haciendo que el cuerpo se forme y cobre forma lejos de su patria. El cuerpo de Novo también es motivo de relato, sobre todo en las fotografías donde el punctum se encuentra en alguna parte del cuerpo: inmensas manos, cejas arqueadas, grandes anillos, que operan la visibilidad de su figura. Novo, por lo tanto, utiliza su cuerpo para exponer otras sensibilidades que se han inmiscuido en la sociedad 
mexicana develando no sólo su exoticidad, sino también su extranjería sexual. Novo interviene su cuerpo por medio de la exhibición de accesorios cosméticos extravagantes (pelucas, anillos) para sexualizarlo por medio de una pulsión exhibicionista que se transforma en una pulsión narrativa. El "archivo plástico" funciona entonces bajo este procedimiento: "Salvador Novo se exhibe y el archivo, a su vez, exhibe cómo Novo se exhibe" (158), por lo tanto, el archivo cobra vida con el pasar del tiempo. El capítulo finaliza con otra fotografía de un desnudo de Salvador Novo en tres secuencias de paneles de vidrio en negativo, sin fecha, por lo que no se puede rastrear las huellas de una escritura anterior, sino que el negativo funciona como un develamiento futuro. El cuerpo, por lo tanto, “niega la territorialización en su dimensión espacial, para asociar la materialidad con el cuerpo" (160), haciendo que el cuerpo se descubra con el pasar del tiempo.

El capítulo tres llamado "Las muñecas de Reverón” analiza el impacto, el rechazo y el asco que la crítica venezolana e internacional han tenido hacia las muñecas del artista venezolano Armando Reverón. Hechas de tamaño natural, con yute y trapo, mostrando los genitales y con nombres propios, las muñecas han provocado el horror que se relaciona con el temor al cuerpo femenino y a los cuerpos no oficiales como el del mestizo e indio. Son muchos los mitos que recorren sobre estas muñecas: que eran compañías sexuales del artista, que fueron creadas para servir de modelos en las pinturas, que eran sus hijas, etc. Frente a la esquizofrenia del artista, nunca se ha tenido una versión oficial de su finalidad creativa y/o uso por parte de Reverón. Para Guerrero, el arte de Reverón, influenciado por Goya y Velásquez, experimenta con la figura humana, específicamente "el cuerpo lujurioso femenino como espacio arcaico y originario" (183), donde las muñecas son modelos que cancelan el enigma de la musa. El punto más interesante, a mi juicio, es la afirmación de Guerrero acerca de las muñecas como la materialidad del cuerpo sin órganos de Deleuze-Guattari: "Definitivamente ellas llaman la atención a causa de su materialidad, por no ser metáfora ni alegoría, por no comunicarse con un afuera sino por ser cuerpos plásticos par excellence" (203). De este modo, las muñecas de Reverón dan 
CATEDRAL TOMADA: Revista de crítica literaria latinoamericana / Journal of Latin American Literary Criticism Reseña. Javier Guerrero, Tecnologías del cuerpo. Exhibicionismo y visualidad en América Latina. IberoamericanaVervuert. Madrid-Fankfurt, 2014.

cuenta de la transformación en cuerpo que pone en cuestión a una materia que se sexúa en la periferia de la norma excribiéndose del cuadro.

El cuarto capítulo, "El retorno del cuerpo. Fernando Vallejo vuelve a Colombia" analiza la obra autoficcional de Vallejo desde la performance del retorno para hacerse de un cuerpo que irrumpe contra las lógicas heterosexistas. Vallejo crea un alter ego escritor llamado Porfirio Barba Jacob desde el cual se crea un cuerpo extranjero que se identifica con la enfermedad para reproducir un cuerpo marcadamente sexual. Se tata de un cuerpo errante y sexuado que retorna a Colombia para reafirmar las marcas de su extranjería adquirida y repudiar las hegemonías sexuales y nacionales. La situación de extranjero se hace evidente en obras como Los caminos a Roma donde el tópico del viaje se realiza desde la perspectiva del turista, pero que se evidencia a partir de la lengua donde, a pesar de estar en un país con su mismo idioma, no se entiende con el resto; y la pérdida del pasaporte como posibilidad de la destrucción de la identidad que lo enviaría a un terreno de inexistencia. Es por ello que la materialidad del cuerpo en Vallejo es irrepresentable; sin embargo, aparecen las marcas que lo van cifrando para “descubrirlo como último reducto del tiempo en sus últimas novelas" (234). Cuando Vallejo vuelve a Colombia, lo hace con quince perros callejeros con quienes aparece en las pocas presentaciones públicas que realiza para exhibirse como un cuerpo callejero que recupera su visibilidad.

Finalmente, "Experimentos de la piel. El cuerpo de Mario Bellatin", el último capítulo de este libro, analiza el cuerpo enfermo en la producción artística de Mario Bellatin donde se representa la materialidad sexuada que se descompone y desestabiliza, pero que también inquieta a la heteronormatividad. Salón de belleza es la obra que habla sobre el Moridero, un antiguo salón que se ha convertido en un lugar donde llegan enfermos terminales cuando su "mal" se ha hecho visible. Por ello, el cuerpo es el tema central, pero es un cuerpo intervenido por la cosmética y la enfermedad que lo convierten en un cuerpo abyecto. Se trata de exhibir un cuerpo que ha sido afectado por la "plaga" (no se nombra la enfermedad, pero se infiere que es VIH) que coloniza estos cuerpos que alguna 
vez fueron bellos. El salón se convierte en espacio de exhibición de cuerpos cosméticamente transformados, pero que la enfermedad los ha reclamado y que ahora resultan irreconocibles. Además funciona como un espacio completamente femenino, aunque el "huésped" sea masculino, rompiendo con el binarismo genérico y reformulando la materia del cuerpo sexuado: "El cuerpo muta haciéndose visible como otredad: la delgadez extrema, la inflamación de los ganglios, el olor, la piel, las llagas descubren otra corporalidad" (249). La somatización de la enfermedad hace visible al salón como un espacio inhabitable donde llegan desechos de cuerpos, ya que el Moridero es el lugar para la experimentación de nuevos cuerpos que retornan a un estadio presubjetivo de sexuación donde se reafirma que no hay sujeto sin género y no hay género sin cuerpo. Otro elemento interesante es lo que Guerrero llama la "pose", no sólo de los cuerpos, sino también del autor: "Bellatin posa para cada uno de sus textos, en algunos ocupa el espacio ficcional (evocado) de sus narradores/personajes [...]; en otros sólo presenta su cuerpo animalizado, fragmentado, en falta" (256), gozando al exhibir su condición de materia alterada. La malformación congénita del autor se exhibe en la intervención de su propio cuerpo al mostrar diferentes tipos de prótesis en su brazo que funcionan como extensión estética del cuerpo hacia el espacio ficcional. La fotografía de Bellatin con prótesis estéticas (puntas curvas, texturas, ramificaciones) y/o provocativas (prótesis en forma de pene) sexualizan esa falta provocando el deseo. La exhibición no sólo hace visible el objeto que falta, sino también que lo exhibido se multiplique y extienda más allá del cuerpo rehaciéndose constantemente.

El libro concluye con una foto de Severo Sarduy que posa con un cuerpo orientalizado desde París; para Guerrero, el punctum de la fotografía es el reloj en su brazo izquierdo, porque detiene el tiempo y por su extranjería con el ambiente oriental que se pretende. Por ello "Volverse irreconocible", como titula la conclusión citando una frase de Novo, es la capacidad de alterar, transformar y modificar los cuerpos. Los autores y artistas seleccionados posan y se exhiben para hacer que sus cuerpos y sus ficciones se vuelvan irreconocibles, haciendo del 
viaje y la extranjería, la enfermedad y el archivo las tres instancias en que el cuerpo se materializa en una plasticidad que cobra forma y da forma para descifrarse y exhibirse.

Este libro me parece que debe encontrarse dentro de la bibliografía obligatoria de aquellos que están trabajando temas acerca de la corporalidad, la sexualidad y la estética latinoamericana. 